\title{
乳腺癌耐药蛋白基因的转录调控机制
}

\author{
吴新刚，彭姝涁，黄谦 \\ 岳阳职业技术学院医学基础部, 岳阳 414000
}

摘要: 乳腺癌耐药蛋白(Breast cancer resistance protein, BCRP), 又名 ABCG2, 是 ATP 结合盒(ATP-binding cassette, $\mathrm{ABC}$ )转运蛋白超家族成员之一, 在肿瘤多药耐药中具有十分重要的作用。BCRP 基因启动子区无 TATA 盒, 含 CAAT 盒、 $\mathrm{AP} 1$ 位点、 $\mathrm{AP} 2$ 位点以及 $\mathrm{CpG}$ 岛下游的多个 $\mathrm{Sp}-1$ 位点。近年来的研究发现, 转录因子㔔激素受 体 $(\mathrm{PR}) 、$ 雌激素受体 $(\mathrm{ER})$ 、核因子 $-\mathrm{kB}(\mathrm{NF}-\mathrm{\kappa B})$ 、缺氧诱导因子 $(\mathrm{HIF}) 、 \mathrm{Nrf} 2$ 、芳香烃受体 $(\mathrm{AhR})$ 、过氧化物酶体 增殖活化受体(PPAR)和 KLF5 等可与 BCRP 启动子或增强子区的特定反应元件结合进而激活 BCRP 的转录。促 炎细胞因子、生长因子、同源盒基因 MSX2、Sonic hedgehog 信号通路、Notch 信号通路和 RAR/RXR 信号通路 等均参与了 $B C R P$ 的转录调控。此外, 启动子甲基化和组蛋白乙酰化在 BCRP 转录调控尤其是药物诱导 BCRP 表达中发挥重要作用。文章综述了这一研究领域的进展, 着重讨论了转录因子及表观遗传学在 BCRP 转录调控 中的作用。

关键词: 乳腺癌耐药蛋白; 转录调控; DNA 甲基化; 转录因子; 多药耐药

\section{Transcriptional regulation of breast cancer resistance protein}

\author{
WU Xin-Gang, PENG Shu-Bin, HUANG Qian
}

Department of Basic Medical Sciences, Yueyang Higher Vocational and Technical College, Yueyang 414000, China

\begin{abstract}
Breast cancer resistance protein (BCRP), also known as ABCG2, is a member of the ATP-binding cassette $(A B C)$ transporter superfamily, and is known to play important roles in cancer multidrug resistance. The BCRP promoter lacks a TATA-box and contains a CAAT-box, lots of AP1, AP2 sites and several putative Sp1 sites which are downstream of a putative $\mathrm{CpG}$ island. Several transcription factors, such as progesterone receptor (PR), estrogen receptor (ER), nuclear factor- $\kappa \mathrm{B}(\mathrm{NF}-\kappa \mathrm{B})$, hypoxia-inducible factors (HIFs), nuclear factor erythroid 2-related factor 2 (Nrf2), aryl hydrocarbon receptor (AhR), peroxisome proliferator-activated receptors (PPARs) and Krüppel-like factor 5 (KLF5), have been recently shown to bind to their response elements in the promoter/enhancer to activate the transcription of BCRP. BCRP transcription can be influenced by proinflammatory cytokines, growth factors, and homeobox protein MSX2. Signaling pathways, such as Sonic hedgehog (Shh), Notch and RAR/RXR pathways, may also involve in the transcriptional regulation of $B C R P$. In addition, promoter methylation and histone acetylation are essential for the BCRP transcription, especially for the drug-induced BCRP expression. This paper reviews the recent research progresses in this field with an emphasis on the
\end{abstract}

收稿日期: 2012-03-20; 修回日期: 2012-05-11

基金项目: 岳阳职业技术学院(编号：YZ1104G)和湖南省教育厅项目(编号：11C1284)资助

作者简介: 吴新刚, 硕士, 讲师, 研究方向 : 乳腺癌分子生物学。Tel: 13873069242; E-mail: wu_alwin@yahoo.com.cn

网络出版时间: 2012/8/30 13:27:50

URL: http://www.cnki.net/kcms/detail/11.1913.R.20120830.1327.003.html 
roles of transcription factors and epigenetics in the transcriptional regulation of BCRP.

Keywords: breast cancer resistance protein (BCRP); transcriptional regulation; DNA methylation; transcription factors; multidrug resistance(MDR)

乳腺癌耐药蛋白(Breast cancer resistance protein, BCRP), 又名胎盘特异性ATP结合盒蛋白(Placentaspecific ATP-binding cassette protein, ABCP)、米托葱 醌耐受相关蛋白(Mitoxantrone resistance-associated protein, MXR)和 $A B C G 2$, 是ATP结合盒(ATP-binding cassette, $A B C)$ 转运蛋白超家族 $\mathrm{G}$ 亚族成员之一。 $B C R P$ 基因(GeneID 9429)于 1998 年由Doyle 等 ${ }^{[1]}$ 自乳腺癌耐药细胞株MCF-7/AdrVp中首次克隆。该 基因定位于人染色体 4q22, 编码 655 个氨基酸残基 组成的跨膜糖蛋白。大规模篮检实验表明, BCRP在 消化道肿瘤、生殖道肿瘤、肺癌、黑色素瘤及急性 白血病等中有较高表达, 并与药物耐受相关。目前 已知的 BCRP 底物有米托葸醌 (MX)、托泊替康 $(\mathrm{TPT}) 、$ 柔红霉素(DNR)、阿霉素 $(\mathrm{ADM})$ 、氨甲喋呤 (MTX)、SN38 和酪氨酸激酶抑制剂等化疗药 物 [2,3]。因此, 研究BCRP转录调控机制对逆转肿瘤多药 耐药(Multidrug resistance, MDR), 提高化疗疗效具 有十分重要的意义。

与 $\mathrm{ABC}$ 转运蛋白超家族其他成员如 $M D R 1$ 和 $M R P 1$ 基因相似, $B C R P$ 基因启动子区无 TATA 盒, 含 CAAT 盒、AP1 位点、AP2 位点以及 $\mathrm{CpG}$ 岛下游的 多个 $\mathrm{Sp}-1$ 位点, 但它们在 $B C R P$ 转录中的作用有待 深入的研究。近年来的研究表明, 多种转录因子如 孕激素受体(Progesterone receptor, PR)、雌激素受体 (Estrogen receptor, ER)、核因子 $-\kappa B($ Nuclear factor- $\kappa B$, $N F-\kappa B$ ) 和缺氧诱导因子 (Hypoxia-inducible factor, $\mathrm{HIF}$ )等可通过与 $B C R P$ 启动子或增强子区的特定反 应元件结合, 参与 $B C R P$ 的转录调控。促炎细胞因 子、生长因子和某些信号通路可调节 $B C R P$ 的表达。 此外, DNA 甲基化和组蛋白乙酰化在 BCRP 转录中 也具有重要作用。本文就近年来 $B C R P$ 的转录调控 机制研究进展进行了简要的概述。

\section{1 与 BCRP 转录相关的转录因子}

\section{1 性激素受体}

$B C R P$ 在胎盘中高表达, 并在妊娠期受到黄体
酮(Progesterone, $\mathrm{P}_{4}$ ) 和 17 $\beta$-雌二醇 $\left(17 \beta\right.$-Estradiol, $\mathrm{E}_{2}$ ) 等妊娠相关激素的严密调控。上述激素与相应受体 结合后导致受体构象改变, 后者与伴侣蛋白如热休 克蛋白 90(Heat shock protein 90, Hsp90)解离并形成 二聚体, 该二聚体结合到 $B C R P$ 启动子区的相应反 应元件进而激活 $B C R P$ 的转录。

\section{$B C R P$ 启动子区 $(-187 /-173)$ 存在孕激素反应元件}

(Progesterone response element, PRE)。通过构建包含 PRE的 BCRP启动子报告基因质粒并转染人胎盘线 毛膜癌细胞系BeWo后发现，在抑制内源性 $\mathrm{P}_{4}$ 的情况 下, 生理浓度的 $\mathrm{P}_{4}$ 可有效激活BCRP启动子活性, 这 种激活作用是 PR依赖性的。BeWo细胞中存在两种 PR亚型即PRA和PRB，其中PRB与上述调节有关 ${ }^{[4]}$ 。 由于PRA可抑制PRB的表达, 因此, 激活PRA反而 可抑制PRB的转录活性。与 $\mathrm{P}_{4}$ 单独处理相比, 联合低 浓度 $\mathrm{E}_{2}$ 可使 $\mathrm{BeWo}$ 细胞中 $B C R P$ 的表达水平明显升高, 其机制可能与 $\mathrm{E}_{2}$ 诱导PRB表达有关。然而, 在不抑制 内源性 $\mathrm{P}_{4}$ 的情况下, 只有高浓度 $\mathrm{P}_{4}$ 才能诱导BeWo细 胞和原代滋养层细胞中 BCRP的表达, 且这一效应 不能被PR拮抗剂RU-486 所抑制 ${ }^{[5]}$ ，上述结果可能 与高浓度内源性 $\mathrm{P}_{4}$ 导致 $\mathrm{PR}$ 处于饱和状态有关。 $\mathrm{PR}$ 与 $\mathrm{Sp} 1$ 的相互作用在 $B C R P$ 的转录调控中可能发挥重要 作用。研究发现, $\mathrm{P}_{4}$ 可激活乳腺癌细胞系 T47D中 $B C R P$ 启动子活性, 但这一效应可被RU-486 和 Sp1 抑制剂光神霉素所消除 ${ }^{[6]}$ 。然而, 最近有研究发现, 乳腺癌组织中 $P R$ 与 $B C R P$ 表达水平呈负相关; $\mathrm{P}_{4}$ 处理 外源性 BCRP过表达 MCF-7 细胞后, 细胞中 BCRP mRNA和蛋白表达水平明显降低, 这一效应与PR结 合PRE进而抑制BCRP表达有关 ${ }^{[7]}$ 。

ER包括由不同基因编码的两种亚型, 即 $E R \alpha$ 和 $E R \beta 。 E_{2}$ 对 $B C R P$ 的转录调控主要是通过 $E R \alpha$ 与雌激 素反应元件(Estrogen response element, ERE)结合所 介导的。研究发现, $\mathrm{E}_{2}$ 可诱导ER阳性T47D:A18 细胞 和稳定表达外源性 $\mathrm{ER} \alpha$ 的卵巢癌细胞系PA-1 中 $B C R P$ 的表达。在 $\mathrm{ER} \alpha$ 阳性的 $\mathrm{MCF}-7$ 细胞中也获 得了类似的结果, 并且抗雌激素药物托瑞米芬以剂 
量依赖性关系下调内源性和外源性BCRP mRNA的 表达水平，同时使细胞对 MX的耐受性降低; 但在 $\mathrm{ER} \alpha$ 阴性乳腺癌细胞系 MDA-MB-231 中, BCRP mRNA的表达水平并没有改变 ${ }^{[8]}$ 。在 BeWo细胞中, 雌酮、 $\mathrm{E}_{2}$ 和䧳三醇以浓度依赖性方式上调 BCRP $m R N A$ 和蛋白表达水平; 由于ERE和PRE重叠, $P_{4}$ 可 以抑制上述作用 ${ }^{[4]}$ 。然而, 有研究 ${ }^{[6,9]}$ 发现, $E_{2}$ 对BeWo 细胞、 T47D细胞、大鼠和小鼠脑微血管中 BCRP mRNA 表达水平无影响，但可通过 $\mathrm{ER} \beta$, PTEN/PI3K/AKT/GSK3 下调BCRP蛋白表达水平。

生理浓度的睪酮对BeWo细胞中 $B C R P$ 的表达无 影响, 但联合 $\mathrm{E}_{2}$ 可显著上调BCRP mRNA和蛋白表 达水平，该效应可被 $\mathrm{ER} \alpha$ 拮抗剂或睪酮受体 (Testosterone receptor，TR)拮抗剂所抑制，提示，上 述作用可能与ER $\alpha$ 诱导TR表达有关 ${ }^{[10]}$ 。

\section{$1.2 \quad \mathrm{NF}-\kappa \mathrm{B}$}

NF- $\kappa$ B由 Rel蛋白家族成员即 $\mathrm{p} 50 、 \mathrm{p} 52 、 \mathrm{p} 65$ (RelA)、RelB和c-Rel等以同源或异源二聚体形式组 成，其中 p $65 / \mathrm{p} 50$ 异源二聚体是最常见的形式。作为 转录因子, NF- $\kappa \mathrm{B}$ 可结合到靶基因上的 $\kappa \mathrm{B}$ 位点进而 调节基因的表达。 $B C R P$ 启动子区存在 NF- $\kappa \mathrm{B}(\mathrm{p} 50)$ 位点 (-27/-18), NF- $\kappa \mathrm{B}$ 通过与该位点结合可激活 $B C R P$ 的表达。在野生型p53(Wild-type p53,wt-p53) 低表达的MCF-7 细胞中, wt-p53 通过抑制NF- $\kappa$ B的 转录活性进而下调BCRP mRNA和蛋白表达水平, 细胞对MX的敏感性明显增加 ${ }^{[11]}$ 。然而, 在 $\mathrm{p} 53$ 缺陷 的骨肉瘤细胞系Saos-2 中, 外源性wt-p53 以NF- $\mathrm{kB}$ 依赖性方式激活BCRP的表达，其机制可能是 $\mathrm{p} 53$ 与 $\mathrm{NF}-\mathrm{\kappa B}$ 可依细胞类型和刺激性质的不同而在功能上 相互协同或拮抗 ${ }^{[12]}$ 。外源性人表皮生长因子受体 2(Human epidermal growth factor receptor 2, HER-2) 过表达MCF-7 细胞中, BCRP表达水平明显升高, 细 胞对紫杉醇(Taxol)、顺铂(DDP)、依托泊苷(VP-16)、 $A D M 、 5$-氟尿嘧啶 $(5-\mathrm{Fu})$ 和MX等的敏感性降低, 但 这一效应可被PI3K抑制剂LY294002、IкB磷酸化抑 制剂Bay 11-7082 和显性负突变 $I \kappa B \alpha$ 所消除 ${ }^{[13]}$ ，提示， HER-2 可能通过 PI3K/AKT/NF- $\mathrm{KB}$ 信号通路激活 $B C R P$ 的转录。

\subsection{HIF}

HIF 由氧调节亚单位HIF- $\alpha$ 和结构亚单位HIF- $\beta$ 组成, 其中HIF- $\alpha$ 既是调节亚基又是活性亚基。常氧
条件下, HIF- $\alpha$ 的脯氨酸残基被脯氨酸差化酶羟基化, 致使HIF- $\alpha$ 与Von Hippel Lindau (VHL)结合, 经泛素 化-蛋白酶体途径降解。缺氧条件下, 脯氨酸羟化酶 活性被抑制, HIF- $\alpha$ 蛋白稳定性增加并转移到细胞核 内，与HIF- $\beta$ 结合组成有活性的HIF，后者募集辅激 活蛋白 CBP/P300 并结合到靶基因启动子区的缺氧 反应元件(Hypoxia response element, HRE), 启动基 因的表达。研究发现, 在缺氧条件下培养的多种肿 瘤细胞和侧群(Side population, SP)细胞中, BCRP mRNA表达水平明显升高, 并且外源性HIF-2 $\alpha$ 以剂 量依赖性关系激活小鼠 $\mathrm{C} 2 \mathrm{C} 12$ 成肌细胞中 BCRP启 动子活性。然而, 在缺氧条件下培养的HIF-1 1 缺失小 鼠细胞系BpRcl中, $B C R P$ 表达水平末见明显改变 ${ }^{[14,15] 。}$ 上述效应与HIF-1 和 HIF-2 结合 BCRP 启动子区的 $\operatorname{HRE}(-2549 /-2528)$ 有关。

\subsection{Nrf2}

核因子E2 相关因子 2(Nuclear factor erythroid 2-related factor 2, Nrf2) 是 $\mathrm{CNC}(\mathrm{Cap}$ 'n'collar)转录因 子家族成员之一。生理条件下, Nrf2 与KEAP1(Kelchlike ECH-associated proteinl)结合而针定于细胞浆 内。氧化应激状态时, KEAP1 构象改变或者Nrf2 发 生磷酸化, 导致两者分离, Nrf2 转移到细胞核内, 与 Maf形成异二聚体，后者识别并结合到抗氧化反应 元件(Antioxidant response element, ARE)上, 启动靶 基因的表达。研究发现, Nrf2 激活剂吡噻硫酮和叔丁 基对苯二酚可上调人原代肝细胞和肝癌细胞系HepG2 中 BCRP mRNA表达水平，而 $\mathrm{Nrf} 2$ 缺陷小鼠的肝细 胞中, $B C R P$ 表达水平明显降低 ${ }^{[16]}$ 。通过ShRNA抑制 肺癌细胞系A549、H460 和前列腺癌细胞系DU145 中 Nrf2 活性后, $B C R P$ 表达水平明显降低, 细胞对 $\mathrm{MX}$ 和 TPT 的敏感性增加; 当抑制肺上皮细胞中 KEAP1 的表达水平进而激活 Nrf2 后, BCRP mRNA 表达水平明显升高。上述效应与 $\mathrm{Nrf2}$ 结合 $B C R P$ 启动 子区的ARE(-431/-420)有关 ${ }^{[17]}$ 。

\section{5 芳香烃受体}

芳香烃受体(Aryl hydrocarbon receptor, AhR)激 动剂如 2,3,7,8-四氯二苯-对-二恶英(TCDD)、苯并 [k] 苂葸 $(\mathrm{B}[\mathrm{k}] \mathrm{F}) 、 3$-甲基胆蒽 (3-MC)和苯并 $[\mathrm{a}]$ 萠 (BP)等 可上调MCF-7、HepG-2、结肠癌细胞系Caco-2、S1和 SW640 等细胞中BCRP mRNA和蛋白表达水平; AhR 
沉默或其拮抗剂如白䔉芦醇、山柰酚和柳酰胺等可 消除上述作用 ${ }^{[18]}$ 上述结果提示, AhR可能在 $B C R P$ 的 转录调控中发挥作用。AhR是一种配体依赖性转录 因子, 无配体时, AhR与Hsp90、p23 以及AhR结合蛋 白形成复合物, 处于非激活状态; 一旦与配体结合, $\mathrm{AhR}$ 解离并转移到细胞核内, 与芳香烃受体核转位 蛋白结合形成二聚体，后者结合到芳香烃受体反应 元件(AhR responsive element, AhRE)上, 进而启动 基因的转录。分析 $\mathrm{BCRP}$ 启动子区序列发现, $B C R P$ 基 因含有 9 个可能的AhRE，其中位于-194/-190 的 $\mathrm{AhRE}$ 与 $\mathrm{AhR}$ 有很强的亲合力, 报告基因实验表明该 反应元件在 $\mathrm{TCDD}$ 和 $\mathrm{B}[\mathrm{k}] \mathrm{F}$ 等诱导 $B C R P$ 表达中起关 键性作用 ${ }^{[18,19]}$ 。组蛋白去乙酰化酶 (Histone deacetylase, HDAC)抑制剂罗米地辛可诱导Hsp90 乙 酰化, 导致 $\mathrm{AhR}$ 与 $\mathrm{Hsp} 90$ 解离并增强 $\mathrm{AhR}$ 与上述 AhRE的亲合力, 因此, 罗米地辛可选择性诱导 $\mathrm{S} 1$ 细 胞中BCRP的表达 ${ }^{[19]}$ 。然而, 上述AhRE与 $3-M C$ 诱导 结肠癌细胞系LS174T中 BCRP的表达无关。研究证 实, 3-MC 是通过增强 $\mathrm{AhR}$ 与 $B C R P$ 增强子区的 $\operatorname{AhRE}(-2357 /-2333)$ 结合进而激活BCRP转录的 [20]。

\section{6 过氧化物酶体增殖活化受体}

过氧化物酶体增殖活化受体(Peroxisome proliferator-activated receptor, PPAR)是一种配体依赖性 转录因子, 包括由不同基因编码的三种亚型, 即 PPAR- $\alpha$ 、PPAR- $\gamma$ 和PPAR- $\delta$ 。PPAR与配体结合后被 激活, 与视黄酸类 $\mathrm{X}$ 受体(Retinoid X receptor, RXR) 结合形成PPAR/RXR异二聚体，后者与靶基因上的 PPAR反应元件(PPAR response element, PPRE)结合, 启动基因的转录。研究发现, PPAR- $\gamma$ 激动剂罗格列 酮、曲格列酮和GW7845 可上调人树突状细胞中 BCRP mRNA表达水平, 导致细胞对MX的耐受性增 强, 而PPAR- $\gamma$ 沉默或其拮抗剂可消除上述作用。进 一步研究显示, BCRP增强子区存在 3 个PPRE, PPAR $-\gamma / R X R \alpha$ 可与之结合进而激活 $B C R P$ 的转录 ${ }^{[21]}$ 。 Hirai等 ${ }^{[22]}$ 报道, PPAR- $\alpha$ 激动剂Wy14643 和GW7647 喂养的野生型PPAR- $\alpha$ 小鼠小肠上皮细胞中, BCRP 表达水平较PPAR- $\alpha$ 缺陷小鼠明显升高。提示, PPAR $-\alpha$ 可能参与了 $B C R P$ 的转录调控。

\subsection{KLF5}

KLF5(Krüppel-like factor 5)是KLF转录因子家 族成员之一。KLF5 沉默肺癌细胞系H441 中, BCRP mRNA表达水平明显升高; 而外源性KLF5 过表达 $\mathrm{H} 441$ 细胞中, $B C R P$ 表达水平明显降低, 上述效应与 KLF5 结合 BCRP 增强子区的 KLF5 结合位点 (-7014/-6999)有关 ${ }^{[23]}$ 。

\section{2 促炎细胞因子与 BCRP 转录}

促炎细胞因子可影响 $B C R P$ 的表达，但这种影 响具有组织特异性。研究发现, 溃疡性结肠炎患者 肠粘膜组织中 BCRP mRNA表达水平与白细胞介素 -6(Interleukin-6, IL-6)水平明显相关。细胞实验证实, IL-6 可使原代肝细胞、宫颈癌细胞系HeLa和人脑微 血管内皮细胞系hCMEC/D3 中BCRP mRNA表达水 平降低, 但不影响 $\mathrm{HeLa}$ 和hCMEC/D3 中 BCRP蛋白 表达水平, 且对 $M X$ 耐药 MCF-7/MX细胞中 BCRP的 表达无影响。IL- $1 \beta$ 和肿瘤坏死因子- $\alpha$ (Tumor necrosis factor- $\alpha, \mathrm{TNF}-\alpha)$ 可使猪脑血管内皮细胞、HeLa、 hCMEC/D3 和原代胎盘滋养层细胞中 BCRP mRNA 表达水平降低, 但对 HeLa和 hCMEC/D3 细胞中 BCRP蛋白表达无明显影响。此外, 它们对胃癌细胞 系EPG85-257 和MCF-7/MX细胞中 BCRP的表达无影 响。然而, 在MCF-7 细胞中, IL- $1 \beta$ 和TNF- $\alpha$ 可上调 BCRP mRNA和蛋白表达水平, IL-6 对BCRP mRNA 表达水平无影响, 但可上调 BCRP蛋白表达水平 [24,25]。

与 $\mathrm{E}_{2}$ 单独处理相比, 联合 TNF- $\alpha$ 可使MCF-7 细 胞中 BCRP mRNA和蛋白表达水平明显升高; 在 TNF- $\alpha$ 存在的情况下, $\mathrm{E}_{2}$ 以剂量依赖性方式激活 $B C R P$ 的表达; TNF- $\alpha$ 单独处理对 $B C R P$ 的表达影响轻 微, 但在 $\mathrm{E}_{2}$ 存在的情况下, TNF- $\alpha$ 以剂量依赖性方式 激活 $B C R P$ 的表达，上述效应是通过 $\mathrm{NF}-\mathrm{\kappa B}$ 与 $\mathrm{ER}$ 的 相互作用(Cross-talk)而介导的。TNF- $\alpha$ 通过活化膜受 体继而活化 I $\kappa \mathrm{B}$ 激酶，后者使 I $\kappa \mathrm{B}-\alpha$ 磷酸化并通过泛 素-蛋白酶体途径降解。NF- $\kappa$ B与I $\mathrm{s} B$ 解聚后, 其核定 位信号暴露, 活化的 NF- $\mathrm{KB}$ 二聚体转移到细胞核内, 与 $B C R P$ 启动子区位于 $E R E$ 附近的 NF- $\mathrm{kB}$ 反应元件 (NFkBRE)结合。但这种结合有赖于ER与ERE的结合,

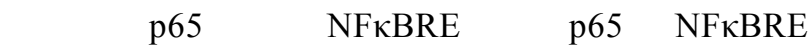


的结合可使ER与ERE的结合更加稳定, 进而增强 $\mathrm{E}_{2}$ 对 $B C R P$ 表达的诱导作用 ${ }^{[26]}$ 。

\section{3 生长因子与 BCRP 转录}

转化生长因子- $\beta$ (Transforming growth factor- $\beta$, TGF- $\beta$ )和表皮生长因子 (Epidermal growth factor, $\mathrm{EGF})$ 可能与 $B C R P$ 转录有关。TGF- $\beta$ 与细胞膜上具有 丝氨酸/苏氨酸激酶活性的受体 T $\beta R$ I 和 T $\beta R$ II 结合 后激活受体，激活的 $\mathrm{T} \beta \mathrm{R} \|$ 磷酸化 $\mathrm{Smad} 2 / 3$, 后者与 Smad4 结合形成Smad2/3-Smad4 复合体并转移到细 胞核内, 参与基因的表达调控。研究发现, TGF- $\beta$ 可 显著下调MCF-7 细胞和胃癌细胞系OCUM-2MLN中 BCRP mRNA表达水平, 上述效应是通过 $\operatorname{Smad} 2 / 3$ 与 $B C R P$ 启动子及增强子区发生特异性结合而介导的 [27]。EGF可诱导BeWo、MCF-7 和原代胎盘滋养层细 胞中 BCRP mRNA的表达, 上述效应与 EGF诱导细 胞中MAP激酶ERK $1 / 2$ 和JNK/SAPK磷酸化有关 ${ }^{[28]}$ 。 然而, Imai等 ${ }^{[29]}$ 报道, EGF通过激活ERK1/2 及其下 游分子RSK进而抑制MCF-7 细胞中 BCRP的转录, 抑 制ERK激酶(MEK)可上调BCRP mRNA表达水平，但 会促进BCRP蛋白的降解。

\section{4 信号通路与 BCRP 转录}

Sonic hedgehog $(\mathrm{Shh})$ 信号通路在 $B C R P$ 转录中发 挥重要作用。神经胶质瘤关联癌基因同源物 1 (Glioma-associated oncogene homolog 1, GLI1)是Shh 信号通路的主要效应蛋白。研究发现, 外源性重组 Shh配体可使食管癌细胞系SEG-1、前列腺癌细胞系 $\mathrm{LnCaP}$ 、人胚肾细胞系293T和弥漫性大 $\mathrm{B}$ 细胞淋巴瘤 细胞中 GLI1 和 BCRP 表达水平明显升高, 细胞对 MTX、Taxol和ADM等的耐受性增强; 通过SiRNA或 Cyclopamine抑制 $G L I 1$ 后, 细胞中 BCRP表达水平降 低, 细胞对MTX、Taxol和ADM等的耐受性随之降 低。上述效应与 GLI1 结合 BCRP启动子区的GLI结合 位点 $(-416 /-408)$ 有关 ${ }^{[30]}$ 。Notch信号通路由Notch受 体、Notch配体和CSL组成。当Notch受体与配体结合 后, 其胞内段 (NICD)被激活, 与细胞膜解离并转移 到细胞核内，与CSL结合形成NICD-CSL复合体，后 者结合到靶基因上的特定序列启动基因转录 ${ }^{[31]}$ 。研 究证实, CSL可与 $B C R P$ 启动子区的CSL结合位点结合 进而激活BCRP的转录 ${ }^{[32]}$ 。此外, RAR/RXR信号通路
可能参与 BCRP的转录调控。研究发现, 全反式维甲 酸、维甲酸受体(retinoic acid receptor, RAR)激动剂 Am580 和RXR激动剂CD2608 均可诱导Caco-2 细胞 中BCRP mRNA的表达 ${ }^{[33]}$ 。

\section{5 表观遗传学与 BCRP 转录}

\subsection{DNA 甲基化}

DNA甲基化是调节基因转录的一种重要表观遗 传修饰方式。研究发现, 骨髓瘤患者标本中 BCRP mRNA表达水平与其等位基因甲基化状态呈负相 关。通过分析细胞中 $B C R P$ 表达水平与其启动子甲基 化状态后发现, BCRP低表达细胞中 $B C R P$ 启动子甲 基化、组蛋白 H3(K9)去乙酰化和甲基化较BCRP中或 高表达细胞明显增加，上述改变促使甲基化 $\mathrm{CpG}$ 结 合蛋白 (MBD2 和 $\mathrm{MeCP} 2)$ 与 $B C R P$ 启动子结合并募集 $\mathrm{HDAC} 1$ 、 $\mathrm{mSin} 3 \mathrm{~A}$ 、 $\mathrm{DNA}$ 甲基转移酶 1(DNA methyltransferase 1, DNMT1)和DNMT3a, 共同形成 转录抑制复合体进而抑制BCRP转录, 同时, 细胞 对MX、TPT和SN-38 的敏感性增加。经DNMT抑制 剂 5-氮脱氧胞苷诱导后, BCRP低表达细胞中 BCRP mRNA和蛋白表达水平明显升高 ${ }^{[34]}$ 。

$B C R P$ 启动子去甲基化是获得性耐药的重要机 制之一。低浓度MX诱导的耐药细胞系MCF-7/wt中, $\mathrm{BCRP}$ 表达水平明显升高。通过检测不同时段细胞中 $B C R P$ 表达水平与 DNA甲基转移酶的变化情况后发 现, DNMT1 和DNMT3a降低与 BCRP过表达密切相 关 ${ }^{[35]}$ 。小细胞肺癌细胞系PC-6 不表达BCRP mRNA, 其 $B C R P$ 等位基因所有 $\mathrm{CpG}$ 位点 $(\mathrm{CpG}$ site)均发生甲 基化。经 SN-38 诱导的耐药细胞系PC-6/SN2-5H中 $B C R P$ 过表达, 与亲代PC-6 细胞相比, BCRP启动子 部分 $\mathrm{CpG}$ 岛去甲基化。Bram等 ${ }^{[36]}$ 发现, $\mathrm{T}$ 细胞急性淋 巴细胞白血病(T-ALL)患者标本和白血病细胞系中 普遍存在 $B C R P$ 启动子甲基化。柳氮磺吡啶和 TPT诱 导耐药细胞系CCRF-CEM中 BCRP启动子完全去甲 基化, $B C R P$ 表达水平明显升高进而介导MDR。

\section{2 组蛋白乙酰化}

组蛋白乙酰化修饰是调节基因转录的关键机制 之一。研究发现, 结肠癌耐药细胞系S1MI80 中, BCRP mRNA和蛋白表达水平较亲代细胞 $\mathrm{S} 1$ 明显升 高; 罗米地辛可诱导 $\mathrm{S} 1$ 细胞中 $B C R P$ 的表达, 但对 
MCF-7、人脑胶质瘤细胞系SF295 和结肠癌细胞系 SW620 中 BCRP 的表达无影响。ChiP分析表明, $\mathrm{S} 1 \mathrm{MI} 80$ 细胞和罗米地辛处理的 $\mathrm{S} 1$ 细胞与其他细胞 相比, BCRP 启动子区组蛋白 H3 $(K 9,14)$ 高乙酰化, $\mathrm{H} 3(\mathrm{~K} 4)$ 三甲基化和 H3(S10)磷酸化增加，而H3(K9) 三甲基化减少，上述改变促使 HDAC1、HDAC3 和 $\mathrm{Sp} 1$ 等与 $B C R P$ 启动子的解离, 促进染色质重塑因子 Brg-1、HAT、辅激活蛋白和RNA多聚酶II与启动子 的结合从而启动基因的转录 ${ }^{[37]}$ 。

\section{6 其他转录调控机制}

研究发现, 多种胰腺癌细胞系中 $B C R P$ 表达水 平与 $M S X 2$ 水平相关, 并且 MSX2 可上调 $B C R P$ 启动 子活性; 当启动子中的 $\mathrm{Sp} 1$ 结合位点突变后, MSX2 的转录激活作用消失; 同时, 在MSX2 过表达细胞 中, $\mathrm{Sp} 1$ 与 $\mathrm{Sp} 1$ 结合位点的结合更加稳定。提示, MSX2 可能通过招募 $S p 1$ 并促进其与 $S p 1$ 结合位点的 结合进而激活BCRP转录 ${ }^{[38]}$ 。最近, 有研究发现, 癌 基因产物 $\mathrm{c}-\mathrm{MYC}$ 可能通过与 $B C R P$ 启动子区的结合 位点结合进而激活BCRP转录 ${ }^{[39]}$ 。此外, 孕烷X受体 (Pregnane X receptor, PXR)、组成型雄烷受体 (Constitutive androstane receptor, CAR)和糖皮质激 素受体(Glucocorticoid receptor, GR)等也可能参与 $B C R P$ 的转录调控 $[40]$ 。

综上所述, $B C R P$ 的转录受到多种转录因子、细 胞因子和生长因子等的调控, 也受某些信号通路的 影响, 而表观遗传学机制是 $B C R P$ 基础表达的主要 机制, 并在 BCRP 介导的获得性耐药中发挥重要作 用。上述研究虽然对 $B C R P$ 的转录机制进行了有益 的探讨, 但存在一些相互矛盾的结论, 而且很多机 制有待更深入的阐明。

\section{参考文献(References):}

[1] Doyle LA, Yang WD, Abruzzo LV, Krogmann T, Gao YM, Rishi AK, Ross DD. A multidrug resistance transporter from human MCF-7 breast cancer cells. Proc Natl Acad Sci USA, 1998, 95(26): 15665-15670. DOI

[2] Natarajan K, Xie Y, Baer MR, Ross DD. Role of breast cancer resistance protein $(\mathrm{BCRP} / \mathrm{ABCG} 2)$ in cancer drug resistance. Biochem Pharmacol, 2012, 83(8): 1084-1103. $\underline{\mathrm{DOI}}$

[3] Noguchi K, Katayama K, Mitsuhashi J, Sugimoto Y.
Functions of the breast cancer resistance protein (BCRP/ABCG2) in chemotherapy. Adv Drug Deliv Rev, 2009, 61(1): 26-33. DOI

[4] Wang H, Lee EW, Zhou L, Leung PC, Ross DD, Unadkat JD, Mao Q. Progesterone receptor (PR) isoforms PRA and PRB differentially regulate expression of the breast cancer resistance protein in human placental choriocarcinoma BeWo cells. Mol Pharmacol, 2008, 73(3): 845-854. DOI

[5] Evseenko DA, Paxton JW, Keelan JA. Independent regulation of apical and basolateral drug transporter expression and function in placental trophoblasts by cytokines, steroids, and growth factors. Drug Metab Dispos, 2007, 35(4): 595-601. DOI

[6] Yasuda S, Kobayashi M, Itagaki S, Hirano T, Iseki K. Response of the ABCG2 promoter in T47D cells and BeWo cells to sex hormone treatment. Mol Biol Rep, 2009, 36(7): 1889-1896. DOI

[7] Wu XJ, Zhang XF, Zhang H, Su P, Li WW, Li L, Wang Y, Liu WJ, Gao P, Zhou GY. Progesterone receptor downregulates breast cancer resistance protein expression via binding to the progesterone response element in breast cancer. Cancer Sci, 2012, 103(5): 959-967. DOI

[8] Zhang YH, Wang HP, Wei LJ, Li G, Yu J, Gao Y, Gao P, Zhang XF, Wei FL, Yin DL, Zhou GY. Transcriptional modulation of BCRP gene to reverse multidrug resistance by toremifene in breast adenocarcinoma cells. Breast Cancer Res Treat, 2010, 123(3): 679-689. DOI

[9] Hartz AMS, Madole EK, Miller DS, Bauer B. Estrogen receptor $\beta$ signaling through phosphatase and tensin homolog/phosphoinositide 3-kinase/Akt/glycogen synthase kinase 3 down-regulates blood-brain barrier breast cancer resistance protein. J Pharmacol Exp Ther, 2010, 334(2): 467-476. DOI

[10] Wang HG, Unadkat JD, Mao QC. Hormonal regulation of BCRP expression in human placental BeWo cells. Pharm Res, 2008, 25(2): 444-452. DOI

[11] Wang XD, Wu XG, Wang CK, Zhang WJ, Ouyang YM, Yu $\mathrm{YH}, \mathrm{He} Z \mathrm{ZM}$. Transcriptional suppression of breast cancer resistance protein (BCRP) by wild-type p53 through the NF- $\kappa \mathrm{B}$ pathway in MCF-7 cells. FEBS Lett, 2010, 584(15): 3392-3397. DOI

[12] 吴新刚，彭姝涁，问四平，张年凤，刍进. p53 对乳腺癌 耐药蛋白基因的转录调控. 中国生物化学与分子生物 学报, 2012, 28(2): 152-157. DOI

[13] Zhang WJ, Ding W, Chen Y, Feng ML, Ouyang YM, Yu $\mathrm{YH}$, He ZM. Up-regulation of breast cancer resistance protein plays a role in HER2-mediated chemoresistance through PI3K/Akt and nuclear factor- $\mathrm{KB}$ signaling pathways in MCF7 breast cancer cells. Acta Biochim Biophys Sin, 2011, 43(8): 647-653. DOI 
[14] Krishnamurthy P, Ross DD, Nakanishi T, Bailey-Dell K, Zhou S, Mercer KE, Sarkadi B, Sorrentino BP, Schuetz JD The stem cell marker Bcrp/ABCG2 enhances hypoxic cell survival through interactions with heme. J Biol Chem, 2004, 279(23): 24218-24225. DOI

[15] Martin CM, Ferdous A, Gallardo T, Humphries C, Sadek H, Caprioli A, Garcia JA, Szweda LI, Garry MG, Garry DJ. Hypoxia-inducible factor- $2 \alpha$ transactivates Abcg2 and promotes cytoprotection in cardiac side population cells. Circ Res, 2008, 102(9): 1075-1081. DOI

[16] Reisman SA, Yeager RL, Yamamoto M, Klaassen CD. Increased Nrf2 activation in livers from Keap1-knockdown mice increases expression of cytoprotective genes that detoxify electrophiles more than those that detoxify reactive oxygen species. Toxicol Sci, 2009, 108(1): 35-47. DOI

[17] Singh A, Wu HL, Zhang P, Happel C, Ma JF, Biswal S. Expression of ABCG2 (BCRP) is regulated by $\mathrm{Nrf2}$ in cancer cells that confers side population and chemoresistance phenotype. Mol Cancer Ther, 2010, 9(8): 2365-2376. DOI

[18] Tan KP, Wang B, Yang MD, Boutros PC, Macaulay J, Xu HB, Chuang AI, Kosuge K, Yamamoto M, Takahashi S, Wu AML, Ross DD, Harper PA, Ito S. Aryl hydrocarbon receptor is a transcriptional activator of the human breast cancer resistance protein (BCRP/ABCG2). Mol Pharmacol, 2010, 78(2): 175-185. DOI

[19] To KKW, Robey R, Zhan ZR, Bangiolo L, Bates SE. Upregulation of $\mathrm{ABCG} 2$ by romidepsin via the aryl hydrocarbon receptor pathway. Mol Cancer Res, 2011, 9(4): 516-527. DOI

[20] Tompkins LM, Li HS, Li LH, Lynch C, Xie Y, Nakanishi T, Ross DD, Wang HB. A novel xenobiotic responsive element regulated by aryl hydrocarbon receptor is involved in the induction of BCRP/ABCG2 in LS174T cells. Biochem Pharmacol, 2010, 80(11): 1754-1761. DOI

[21] Szatmari I, Vámosi G, Brazda P, Balint BL, Benko S, Széles L, Jeney V, Özvegy-Laczka C, Szántó A, Barta E, Balla J, Sarkadi B, Nagy L. Peroxisome proliferator-activated receptor $\gamma$-regulated ABCG2 expression confers cytoprotection to human dendritic cells. J Biol Chem, 2006, 281(33): 23812-23823. DOI

[22] Hirai T, Fukui Y, Motojima K. PPAR $\alpha$ agonists positively and negatively regulate the expression of several nutrient/drug transporters in mouse small intestine. Biol Pharm Bull, 2007, 30(11): 2185-2190. DOI

[23] Meyer SE, Hasenstein JR, Baktula A, Velu CS, Xu Y, Wan HJ, Whitsett JA, Gilks CB, Grimes HL. Krüppel-like factor 5 is not required for K-RasG12D lung tumorigenesis, but represses ABCG2 expression and is associated with better disease-specific survival. Am J Pathol, 2010, 177(3): 1503-1513. DOI

[24] Mosaffa F, Kalalinia F, Lage H, Afshari JT, Behravan J. Pro-inflammatory cytokines interleukin- $1 \beta$, interleukin 6 , and tumor necrosis factor- $\alpha$ alter the expression and function of ABCG2 in cervix and gastric cancer cells. Mol Cell Biochem, 2012, 363(1-2): 385-393. DOI

[25] Poller B, Drewe J, Krähenbühl S, Huwyler J, Gutmann H. Regulation of BCRP (ABCG2) and P-glycoprotein (ABCB1) by cytokines in a model of the human bloodbrain barrier. Cell Mol Neurobiol, 2010, 30(1): 63-70. DOI

[26] Pradhan M, Bembinster LA, Baumgarten SC, Frasor J. Proinflammatory cytokines enhance estrogen-dependent expression of the multidrug transporter gene ABCG2 through estrogen receptor and $\mathrm{NF \kappa B}$ cooperativity at adjacent response elements. J Biol Chem, 2010, 85(41): 31100-31106. DOI

[27] Ehata S, Johansson E, Katayama R, Koike S, Watanabe A, Hoshino Y, Katsuno Y, Komuro A, Koinuma D, Kano MR, Yashiro M, Hirakawa K, Aburatani H, Fujita N, Miyazono K. Transforming growth factor- $\beta$ decreases the cancer-initiating cell population within diffuse-type gastric carcinoma cells. Oncogene, 2011, 30(14): 1693-1705. DOI

[28] Yin LQ, Castagnino P, Assoian RK. ABCG2 expression and side population abundance regulated by a transforming growth factor $\quad \beta$-directed epithelial-mesenchymal transition. Cancer Res, 2008 , 68(3): 800-807. DOI

[29] Imai Y, Ohmori K, Yasuda S, Wada M, Suzuki T, Fukuda $\mathrm{K}$, Ueda Y. Breast cancer resistance protein/ABCG2 is differentially regulated downstream of extracellular signal-regulated kinase. Cancer Sci, 2009, 100(6): 1118-1127. $\underline{\text { DOI }}$

[30] Singh RR, Kunkalla K, Qu C, Schlette E, Neelapu SS, Samaniego F, Vega F. ABCG2 is a direct transcriptional target of hedgehog signaling and involved in stroma-induced drug tolerance in diffuse large B-cell lymphoma. Oncogene, 2011, 30(49): 4874-4886. DOI

[31] Zheng MH, Zhang ZF, Zhao XC, Ding YQ, Han H. The Notch signaling pathway in retinal dysplasia and retina vascular homeostasis. J Genet Genomics, 2010, 37(9): 573-582. DOI

[32] Bhattacharya S, Das A, Mallya K, Ahmad I. Maintenance of retinal stem cells by Abcg2 is regulated by notch signaling. J Cell Sci, 2007, 120(15): 2652-2662. DOI

[33] Hessel S, Lampen A. All-trans retinoic acid enhances the transport of phase II metabolites of benzo[a]pyrene by inducing the Breast Cancer Resistance Protein expression 
in Caco-2 cells. Toxicol Lett, 2010, 197(2): 151-155. DOI

[34] To KKW, Zhan Z, Bates SE. Aberrant promoter methylation of the ABCG2 gene in renal carcinoma. Mol Cell Biol, 2006, 26(22): 8572-8585. DOI

[35] Ji NN, Yuan JH, Liu JJ, Tian SL. Developing multidrug-resistant cells and exploring correlation between BCRP/ABCG2 over-expression and DNA methyltransferase. Acta Biochim Biophys Sin, 2010, 42(12): 854-862. $\underline{\mathrm{DOI}}$

[36] Bram EE, Stark M, Raz S, Assaraf YG. Chemotherapeutic drug-induced ABCG2 promoter demethylation as a novel mechanism of acquired multidrug resistance. Neoplasia, 2009, 11(12): 1359-1370. DOI

[37] To KKW, Polgar O, Huff LM, Morisaki K, Bates SE. Histone modifications at the $A B C G 2$ promoter following treatment with histone deacetylase inhibitor mirror those in multidrug-resistant cells. Mol Cancer Res, 2008, 6(1):
151-164. DOI

[38] Hamada S, Satoh K, Hirota M, Kanno A, Umino J, Ito H, Masamune A, Kikuta K, Kume K, Shimosegawa T. The homeobox gene MSX2 determines chemosensitivity of pancreatic cancer cells via the regulation of transporter gene ABCG2. J Cell Physiol, 2012, 227(2): 729-738. DOI

[39] Porro A, Iraci N, Soverini S, Diolaiti D, Gherardi S, Terragna $\mathrm{C}$, Durante $\mathrm{S}$, Valli $\mathrm{E}$, Kalebic $\mathrm{T}$, Bernardoni $\mathrm{R}$, Perrod C, Haber M, Norris MD, Baccarani M, Martinelli G, Perini G. c-MYC oncoprotein dictates transcriptional profiles of ATP-binding cassette transporter genes in chronic myelogenous leukemia $\mathrm{CD} 34^{+}$hematopoietic progenitor cells. Mol Cancer Res, 2011, 9(8): 1054-1066. DOI

[40] Petropoulos S, Gibb W, Matthews SG. Breast cancer-resistance protein (BCRP1) in the fetal mouse brain: development and glucocorticoid regulation. Biol Reprod, 2011, 84(4): 783-789. DOI

\section{・综合信息・}

\section{八届三次《遗传》编委会议在昆明召开}

2012 年 12 月 1 日下午,“八届三次《遗传》编委会议”在昆明云安会都召开，执行主编张永清、副主编褚嘉祐、 李巍、张勤、编委方向东、何凤田、赫崇波、胡松年、李家乐、李庆伟、刘钢、苗龙、石春海、施鹏、王义权、肖春 杰、徐存拴、杨永华、张博、张根发、朱友林等参加了会议。中国遗传学会办公室主任王长城、《遗传》编辑部主任李 绍武、副主任张颖与陈晓芳、张艳编辑参加了会议。

执行主编张永清研究员主持会议，首先向优秀编委张博、褚嘉祐、张勤、刘钢编委颁发了荣誉证书。

《遗传》编辑部主任、专职副主编李绍武从编委会建设、编辑部建设、期刊出版工作和思考与讨论四个方面作了 第八届编委会工作报告。

到会编委就期刊的发展问题展开了热烈讨论：大家认为《遗传》这本中文期刊定位很好，为年轻人提供了一个很 好的展示平台。同时编委们就录取的综述文章提出了明确的要求，指出应该由相关领域的专家亲自执笔或指导，不要 由研究生写, 希望编委们在任期内至少贡献一篇本领域研究进展的综述文章, 不追求影响因子和稿件数量, 但是要有 自己的特色。编委们对期刊的发表周期提出了很好的建议，希望快速发表能成为《遗传》的一个亮点，以吸引更好的 稿源。同时有的编委还提出可以适当发一些有争议的文章，以引导学术讨论。

会议认为, 由编委负责稿件处理的方式可以接受，这样可对稿件的送审有更好地把握，更充分地发挥编委会的作

用。会议决定稿件送审可以由编辑部灵活掌握, 采取两条腿走路的方针, 编辑部送审与编委送审相结合。

会议决定，2013 年组织出版 1 期“表观遗传学研究专刊”。

会议还向编委们介绍了编辑部新任副主任张颖博士。

会议达到了预期的效果，取得了圆满的成功。 

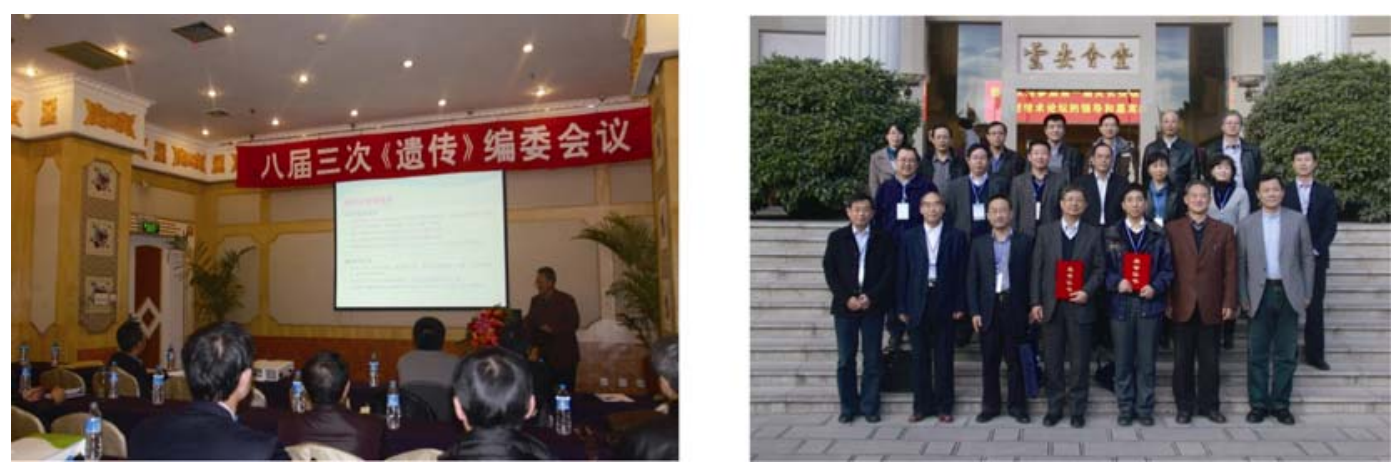